\title{
Modelling the Influence of Product Development on Business Performance and Competitiveness in Manufacturing Enterprises
}

\author{
Mihalj BAKATOR, Dejan ĐORĐEVIĆ, Dragan ĆOĆKALO
}

\begin{abstract}
In this paper the influence of product innovation and development on business performance and competitiveness in small and medium-sized manufacturing enterprises is addressed. The research was conducted via survey and it included over 2200 manufacturing enterprises from Serbia. The number of returned and usable surveys was 132 (5.98\% return rate). The regression model included product development and innovation as two important engineering endeavours and business performance and competitiveness. Additionally, product quality, quality management system (QMS) and human resource management (HRM) were included in the data analysis. The results indicate that the observed relationships between the measured constructs are different, and they depend on how many employees the enterprise has. This paper contributes to the existing body of literature, provides a solid basis for future research in this domain, and other researchers and managers can use this paper as an insight to the relationships between important business metrics.
\end{abstract}

Keywords: business performance; competitiveness; manufacturing enterprises; product development; product innovation; quality management system

\section{INTRODUCTION}

Innovation of products and services is a crucial component of achieving competitiveness [17]. The process of innovation is a step forward towards satisfying customers' needs and expectations. For an enterprise, innovation should not be just a matter of engineering through which the product and service are redesigned, modified or objectively improved. Rather, innovation is a strategic asset, which helps to achieve competitiveness. On the market, customers are influenced by various factors. Enterprises have to answer to the newly developed needs of customers through product innovation and new product development [29], in order to achieve a competitive position. However, are innovation and product development sufficient for a strong position on the market? Certainly, engineering new products and services is beneficial. In addition, there are other factors which play an important role in achieving competitiveness, and overall business performance. For example, human resource management (HRM) may influence operational performance, and overall business performance [21-23]. Besides innovation and development, product and service quality are almost an imperative for satisfying customers, as product and service quality positively affect customer loyalty.

Furthermore, according to the research conducted by Psomas and Kafetzopoulos [26], ISO 9001 certified companies can achieve higher levels of customer satisfaction, operational performance, and market performance. This indicates that implementing quality management systems (QMS) has a positive impact on several metrics of business performance. Additionally, it was noted that implementing a QMS or ISO 9001 standard, the enterprise enjoys a higher level of competitiveness on the market [10]. ISO 9001 certification positively affects operational performance and productivity in the company. It is evident that well implemented QMS can contribute to business performance as well as other performance metrics. The importance of meeting customers' demands lies in the proposition that business excellence and competitiveness can be achieved only through satisfied customers [25]. Surely, there are other factors as well that contribute to competitiveness. The enterprise's strategy, competition on the market, country, national culture, chain companies and other factors can also affect the level of sustainable competitive advantage [24]. One more important factor is the changing market environment, which is further affected by the changes on a global scale. As these changes cannot be observed without including more macro-economic factors, in this present paper the focus is on the micro-factors that can affect business performance and competitiveness on the market.

In this study, the influence of product development and innovation on business performance is addressed. In addition, product quality, QMS and HRM are included as mediating factors. Over 2200 small and medium-sized enterprises (SMEs) from Serbia were included in the research. A total of 132 SMEs returned usable surveys. The main tools for data analysis were three different variants of regression analysis and correlation analysis. The main idea was to determine in what degree the fore-mentioned factors affect business performance and competitiveness of manufacturing enterprises on the market. The paper consists of four main sections (not counting the Introduction and Conclusion sections). The first section provides a theoretical background for the research and introduces the hypotheses. The second section presents the methodology of the research. This includes the sample, survey and data analysis. The third section presents the obtained results from the data analysis and briefly comments on them. The fourth section discusses the findings and highlights the contribution of the research.

\section{THEORETICAL BACKGROUND AND HYPOTHESES DEVELOPMENT}

2.1 The Importance of Product Development and Innovation

Organizations have to adapt when facing dynamic changes on the market [13]. One way to increase the competences of a company on the market is by developing and innovating products and services [5]. Now, if enterprises face difficulties on the market, developing new products that satisfy the needs of customers can improve competitiveness. The question is: Are there other solutions 
for the lack of competitive advantage on the market? Surely, there are. Renewing organizational competencies is one of them and it is no easy task, and enterprises have to face a large set of challenges. Improving the pricing strategy, advertising strategy and other business aspects can also positively affect business performance and competitiveness [13]. In the present paper the focus is on the crucial role of product/service development and innovation in achieving business performance.

Sustained competitiveness on the market is more often achieved through continuous development and innovation of products [7]. The innovation process includes technical and organizational resources where the input is transformed into an improved output. This output can be new products and services that have the goal to satisfy customers. Therefore it can be proposed that customer satisfaction can be the result of thorough engineering of products and services.

Product development is a complex process which involves a large set of technical and organizational approaches. The whole product engineering process involves resources in the form of time, money, employee skills and various operational processes in the enterprise. Basically, enterprises have to invest into products and services so they could increase the chance of acquiring a better market position. The higher levels of research and development processes positively affect business performance and competitiveness as the number of innovations is higher and new products and services are more often placed on the market [1]. This means, the more products are on the market, the higher the probability that these products and services will ensure a stable flow of revenue.

When it comes to technical innovation of products, a structured innovation strategy has proven to produce better results compared to non-strategic innovation [30]. Enterprises have to consider their goals and to develop their strategies accordingly. This process is important as it will determine future business actions.

Innovation culture is one more factor that positively affects the whole innovation process and the overall competitiveness of the enterprise. SMEs that nurture an innovation culture are prone to take higher risks, and have lower resistance to change [19]. Based on the mentioned previous findings it is evident that product innovation and development both as engineering, technical and organizational actions have the power to affect business performance and competitiveness. The question is: How strong is this influence and what other factors play a role in this relationship? To answer this, a thorough data analysis should be conducted, and before that, additional literature is addressed.

\subsection{Quality Management Systems and Product Quality}

Quality management systems (QMS) or ISO 9001 QMS presents a significant approach that helps enterprises to achieve higher and more consistent product and service quality [15]. Enterprises often consider the implementation of ISO 9001 QMS when they want to expand to international markets. This QMS approach is the potential to increase the competitiveness of the enterprise by providing proof of continuous product and service quality.
However, the presence of malpractices in the ISO 9001 QMS certification process can cause concerns when it comes to the benefits that the QMS brings for the enterprise [26]. This means that there are situations when acquiring the certificate is more important for the enterprise than genuinely achieve continuous product quality.

QMS as a philosophy and as an operational and engineering concept has the aim to continuously improve the quality of products and services [14].

It was noted that QMS when used daily can positively affect business performance. The QMS can act as a catalyst for change in the enterprise in order to efficiently adapt to changes on the market [14]. Furthermore, ISO 9001 QMS has been linked to market performance, product and service quality and financial performance [15].

Now, it is evident that QMS has a relationship with business performance and competitiveness. This is why QMS is included in the research as a mediating construct. It would be interesting to see in what way QMS affect business performance and competitiveness when observing product development and innovation as the main construct.

\subsection{Human Resources Management and its Impact on Competitiveness}

When it comes to human resources management (HRM) several studies argued that HRM positively affects business performance $[9,11]$. Similarly the research conducted by [27] discussed that HRM has a positive impact on business performance.

However, it was noted that HRM has only a moderate influence on organizational performance and overall business performance [4].

Strategic HRM is a concept which includes: managing employees based on available resources in the enterprise; achieving high operational performance; managing with a high level of commitment; and managing with a high level of employee participation in achieving the defined goals [18].

Furthermore, an effective HRM has a positive effect on financial performance [2]. Interestingly, it was noted that adequate HRM practices increase profitability, and level of innovation of products and services in SMEs [28].

Certainly, effectively implementing and applying an effective HRM system, the enterprise can achieve higher level of competitiveness, strategic performance, and overall business performance [8]. Employees in the company are a crucial asset for developing high quality products and services. Without them, the enterprise is just an "empty shell" that cannot compete on the market. This is why intellectual capital and knowledge within an enterprise are also important.

With the HRM the theoretical background for the research is completed. Previous studies suggest that all the measured constructs in the present paper have the potential to affect business performance metrics and competitive power on the market.

Why are these constructs important? Well, defining the relationships between diverse technical and organizational constructs such as product development and innovation on the one side and organizational constructs such as business performance and competitiveness, is interesting as there is 
scarcity of publications that address this relationship in this way.

\subsection{Business Performance and Achieving Competitiveness on the Market}

Business performance was found to be connected with market orientation through the technical process of product and service innovation [16]. It can be argued that business performance is an organizational metric, however, it is the result of various other factors that have engineering background, especially in the tech industry.

To achieve good business performance, companies have various options. For example, the concept of total quality management (TQM) has the potential to improve employee participation, operating procedures, productivity, product and service quality, and customer satisfaction. All this results in overall better business performance [33].

SMEs are considered a crucial factor for economic growth. Therefore, high competitiveness for these enterprises is an imperative for long-term survival on the market. Developing good business strategies becomes a necessity for sustaining a good competitive position on the market [29]. Achieving competitiveness sometimes seems to rely on organizational values and marketing strategies of the enterprise. However, technical and engineering metrics in the enterprise can and often have a higher impact on the end result which in this case is business performance and competitiveness.

In the research of Olson, Slater and Hult [20] it was noted that different business strategies result in different structural designs. These structural designs will determine in what degree the enterprise adapts to sudden changes on the market, and how development of products and services will affect future position on the market. It can be seen that business performance is affected by various factors. What factor will affect it the most, cannot be precisely predicted. In this research several factors are included in order to create a "broader picture" of the relationship between the measured constructs.

\subsection{Research Framework and Hypotheses Development}

The research framework of this study includes five measured constructs. In addition, the hypothesized relationships between these constructs are included. In Fig. 1 , the research framework is depicted.

Based on the literature analysis the following hypotheses are proposed:

- $\mathrm{H}_{0}$ : Product development and innovation has a positive influence on business performance and competitiveness.

- $\mathrm{H}_{\mathrm{a}}$ : Product development and innovation does not have an influence on business performance and competitiveness.

- $\mathrm{H}_{1}$ : Product development and innovation is in a positive relationship with the quality management system.

- $\mathrm{H}_{2}$ : Product development and innovation is in a positive relationship with product quality.
- $\mathrm{H}_{3}$ : Product development and innovation is in a positive relationship with human resource management.

- $\mathrm{H}_{4}$ : The quality management system positively affects product quality.

- $\mathrm{H}_{5}$ : The quality management system positively affects human resource management.

- $\mathrm{H}_{6}$ : Product quality has a positive relationship with business performance and competitiveness.

- $\mathrm{H}_{7}$ : Human resource management has a positive relationship with business performance and competitiveness.

- $\mathrm{H}_{8}$ : The quality management system positively affects business performance and competitiveness.

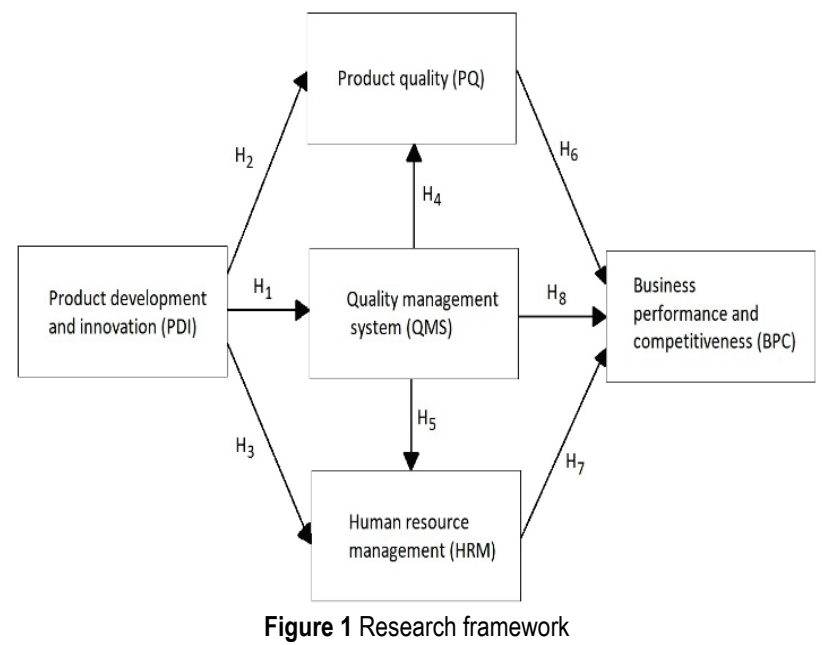

The main focus of this research is the impact of product development and innovation on business performance and competitiveness. The research framework depicts the relationships between the main and mediating constructs. Further, the data analysis took into consideration these mediating constructs and the calculations were conducted accordingly. This approach is not often seen in existing literature as business performance and competitiveness are often interlaced with other factors that are present in the enterprise. Therefore, this approach is justified.

\section{METHODOLOGY}

\subsection{Sample and Survey}

For this research, surveys were sent to 2204 SME managers in Serbia. The number of returned and usable surveys was $132(N=132 ; 5.98 \%$ return rate). The SMEs were contacted via e-mail, and their addresses were obtained from the Economic Directory of Serbia. Further, the sample consisted of enterprises with up to 10 employees all the way to 250 employees. Managers or owners of these enterprises provided data about various business metrics.

The survey itself included 41 Likert scale questions. Additionally, information about gender, age, and number of employees was obtained. The constructs included in the survey were product development and innovation (PDI), product quality (PQ), quality management system (QMS), human resource management (HRM), and business performance and competitiveness (BPC). The Likert-scale 
type questions for the survey were based on other studies in this domain $[3,6,32]$. After the data was obtained a thorough data analysis was conducted.

\subsection{Data Analysis}

The data was analysed in several ways. First, descriptive statistics was used to briefly present the mean values and the mean deviation of the sample. Next, a correlation analysis was conducted in order to address potential multi-collinearity. After the correlation analysis, several variations of regression analysis were conducted. An OLS regression was conducted which included all the mediating factors at once.

Next, another OLS regression analysis was used but here, controls (age, gender, and number of employees) were used. For every mediating construct a separate regression was conducted. With the same approach an ordered regression analysis was conducted. This way the results are validated and there is a smaller chance for errors when the results are interpreted. All the measured constructs were included in every statistical data analysis. For the regression analyses, a model was developed that depicts the potential relationship between the analysed constructs.

Finally, a reliability test was done in order to determine the internal consistency of the items used in the survey.

\section{RESULTS}

The first data analysis tool was descriptive statistics. In Tab. 1, the results of the descriptive statistics are presented.

Table 1 Results of the descriptive statistics

\begin{tabular}{|l|c|c|c|c|}
\hline \multicolumn{1}{|c|}{ Dimension } & Min. & Max. & $\begin{array}{c}\text { Mean } \\
(\mu)\end{array}$ & $s$ \\
\hline $\begin{array}{l}\text { Product development and innovation } \\
\text { (PDI) }\end{array}$ & 1 & 7 & 4,55 & 0.85 \\
\hline Product quality (PQ) & 1 & 7 & 5,98 & 0.56 \\
\hline Quality management system (QMS) & 1 & 7 & 5,59 & 0.77 \\
\hline Human resource management (HRM) & 1 & 7 & 5,51 & 0.64 \\
\hline $\begin{array}{l}\text { Business performance and } \\
\text { competitiveness (BPC) }\end{array}$ & 1 & 7 & 5,04 & 0.72 \\
\hline
\end{tabular}

Table 2 Results of the correlation analysis

\begin{tabular}{|c|c|c|c|c|c|}
\hline \multicolumn{7}{|c|}{ Correlation analysis } \\
\hline & PDI & PQ & QMS & HRM & BPC \\
\hline PDI & $1.000^{*}$ & & & & \\
\hline PQ & $0,307^{*}$ & $1.000^{*}$ & & & \\
\hline QMS & $0,102^{*}$ & $0,404^{*}$ & $1.000^{*}$ & & \\
\hline HRM & $0,284^{*}$ & $0,439^{*}$ & $0,209^{*}$ & $1.000^{*}$ & \\
\hline BPC & $0,485^{*}$ & $0,398^{*}$ & $0,183^{*}$ & $0,484^{*}$ & $1.000^{*}$ \\
\hline
\end{tabular}

* Significance 5\%

Here, the results included the minimum and maximum values, the mean values and the mean deviation $(s)$ values. The mean deviation values range from 0.56 to 0.85 . Given the ordinal nature of the data, these values are acceptable as such.

Furthermore, a correlation analysis was conducted. Every measured construct was included. The significance level was set to $5 \%$. The results of the correlation analysis are presented in Tab. 2 .

Between the two main observed constructs product development and innovation (PDI) and business performance and competitiveness (BPC) there is a positive, moderately strong correlation $(0,485)$. Interestingly the lowest correlation value $(0,102)$ is noted between PDI and quality management system (QMS). Business performance and competitiveness (BPC) is least correlated with QMS, while it has a stronger positive correlation with product quality (PQ) and human resource management (HRM), with the values of 0,398 and 0,484 respectively.

Now, does correlation mean causation? Not necessarily. However the literature in this domain suggests that these business metrics (PDI, PQ, QMS and HRM) are indeed present when it comes to measuring business performance and competitiveness. The correlation analysis is also visually depicted through a scatter plot. BPC is projected on the $Y$ axis, while PDI, QMS, PQ and HRM are projected on the $X$ axis. In addition a linear trendline of PDI is projected on the plot. The scatter plot is shown in Fig. 2.

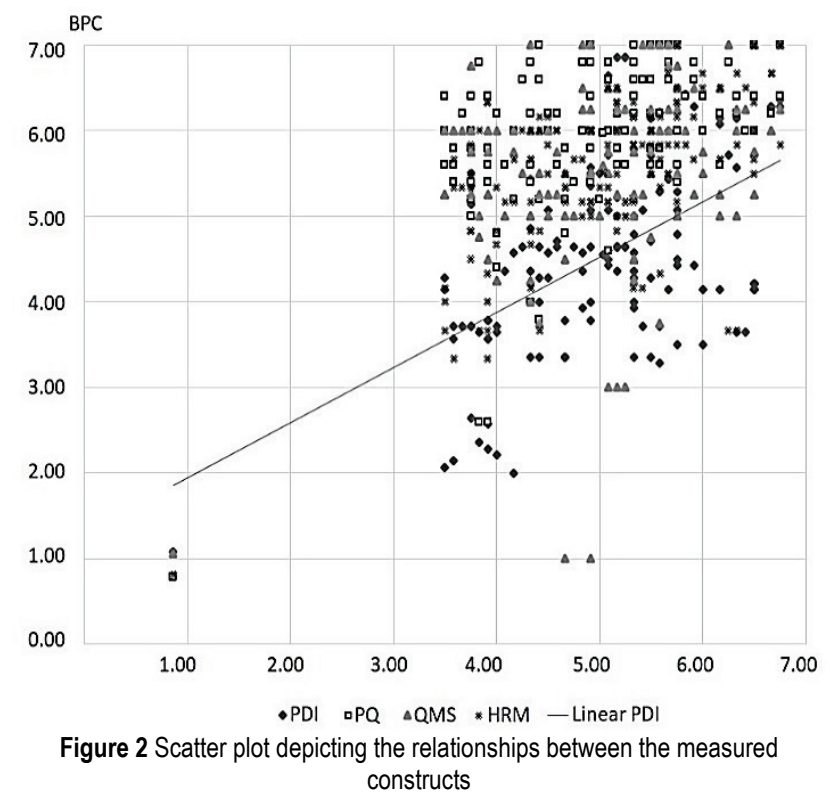

Next, an OLS regression analysis was conducted that included all the mediating constructs (PQ, QMS, and HRM) without controls. The results are presented in Tab. 3.

Table 3 Results of the OLS regression analysis (without controls)

\begin{tabular}{|c|c|c|c|c|c|c|}
\hline \multicolumn{7}{|c|}{ Regression analysis } \\
\hline$Y$ & $X$ & $\beta$ & $p$-value & $R^{2}$ & $F$ & $F$ Sig. \\
\hline \multirow{4}{*}{ BPC } & PDI & 0,280 & $<0,001$ & & & \\
\cline { 2 - 5 } & PQ & 0,176 & 0,052 & & & \\
\cline { 2 - 4 } & QMS & 0,025 & 0,68 & \multirow{3}{*}{0,475} & 28,99 & $<0,001$ \\
\cline { 2 - 4 } & HRM & 0,354 & $<0,001$ & & & $<0,00$ \\
\hline
\end{tabular}

For this regression, the business performance and competitiveness (BPC) construct was observed as the dependent variable $(Y)$, while the other constructs (PDI, PQ, QMS, and HRM) are taken as independent variables $(X)$. An overall regression value of $R^{2}=0,475$ was obtained. This value alone provides a fragment of an insight on the relationship between these variables. If the $p$-values are observed, the QMS variable creates room for concern as the $p$-value is 0,68 which indicates that the QMS variable is statistically insignificant. In order to address this issue, a more complex OLS regression analysis was conducted where controls are introduced (age, gender 
and number of employees) and the mediating constructs are separately "cycled through" a predefined regression model.

The model used for the second OLS regression and the ordered regression has the following form:

$\mathrm{BPC}=\alpha_{0}+\alpha_{1} \cdot \mathrm{PDI}+\alpha_{2} \cdot \mathrm{PDI} \cdot z+x \cdot \gamma+\varepsilon$

where $z=\mathrm{PQ}$, QMS, and HRM, are presented as separate regressions. The $x$ value is the control, and in this case the sample was split-up based on the age of the surveyed manager, the manager's gender and the number of employees in the enterprise. The results of this second OLS regression analysis are presented in Tab. 4.

Table 4 Results of the OLS regression analysis (with controls)

\begin{tabular}{|c|c|c|c|c|c|}
\hline$z$ & Control & $R^{2}$ & Adj. $R^{2}$ & MSE & RMSE \\
\hline PQ & up to 10 emp. & 0,503 & 0,483 & 0,422 & 0,649 \\
\hline PQ & 10 to 50 emp. & 0,170 & 0,143 & 0,595 & 0,772 \\
\hline PQ & 50 to 250 emp. & 0,610 & 0,539 & 0,316 & 0,562 \\
\hline PQ & Male & 0,326 & 0,305 & 0,540 & 0,735 \\
\hline PQ & Female & 0,290 & 0,267 & 0,523 & 0,723 \\
\hline & & & & & \\
\hline QMS & up to 10 emp. & 0,481 & 0,459 & 0,441 & 0,664 \\
\hline QMS & 10 to 50 emp. & 0,067 & 0,036 & 0,670 & 0,818 \\
\hline QMS & 50 to $250 \mathrm{emp}$. & 0,747 & 0,702 & 0,205 & 0,453 \\
\hline QMS & Male & 0,223 & 0,199 & 0,622 & 0,789 \\
\hline QMS & Female & 0,288 & 0,264 & 0,525 & 0,725 \\
\hline & & & & & \\
\hline HRM & up to $10 \mathrm{emp}$. & 0,651 & 0,637 & 0,296 & 0,544 \\
\hline HRM & 10 to 50 emp. & 0,095 & 0,065 & 0,650 & 0,806 \\
\hline HRM & 50 to $250 \mathrm{emp}$. & 0,582 & 0,506 & 0,339 & 0,582 \\
\hline HRM & Male & 0,377 & 0,358 & 0,489 & 0,706 \\
\hline HRM & Female & 0,358 & 0,337 & 0,473 & 0,688 \\
\hline
\end{tabular}

According to the results in Tab. 4, it can be seen that depending on the number of employees, mediating factors and controls, the $R^{2}$ values vary from 0,095 to 0,747 . Before the $R^{2}$ values are further analysed, the MSE and RMSE values are observed. The MSE and RMSE values indicate that this model has a good fit, as the maximum error here is 0,670 for MSE, and 0,818 for RMSE. Given that the maximum value of the ordinal data is 7 , these errors are acceptable.

Further, the mediating constructs and controls are analysed. First, product quality (PQ) is observed. The highest regression value $(0,610)$ is noted with companies that employ 50 to 250 employees, while the lowest regression value $(0,170)$ is measured with companies that have 10 to 50 employees. When it comes to men as managers, they see product quality as more important for business performance compared to women managers. Next, quality management system (QMS) is observed. Here, a high regression value is obtained when evaluating companies with 50 to 250 employees. However, it seems that there are uncomplimentary values as well. Namely, when QMS is observed, and the 10 to 50 employees control is introduced, the regression value falls down to 0,067 , which basically indicates a non-existent relationship between the variables. A similar situation is when HRM is observed, and the 10 to 50 employees control is introduced. Here, the $R^{2}$ value is 0,095 .

These two instances of regression analyses may be due to sampling error, or even more interestingly, it seems that in this case the QMS and HRM factors do not affect BPC when the company has 10 to 50 employees. To further investigate, an ordered regression analysis was conducted. The results are presented in Tab. 5 .

Table 5 Ordered regression analysis

\begin{tabular}{|c|c|c|c|c|}
\hline$z$ & Control & $\begin{array}{c}R^{2} \\
\text { McFadden }\end{array}$ & $\begin{array}{c}R^{2} \\
\text { Cox and Snell }\end{array}$ & $\begin{array}{c}R^{2} \\
\text { Nagelkerke }\end{array}$ \\
\hline PQ & up to 10 emp. & 0,131 & 0,565 & 0,566 \\
\hline PQ & 10 to $50 \mathrm{emp}$. & 0,025 & 0,148 & 0,149 \\
\hline PQ & 50 to $250 \mathrm{emp}$. & 0,181 & 0,572 & 0,577 \\
\hline PQ & Male & 0,052 & 0,290 & 0,291 \\
\hline PQ & Female & 0,051 & 0,279 & 0,280 \\
\hline QMS & up to 10 emp. & 0,120 & 0,531 & 0,532 \\
\hline QMS & 10 to $50 \mathrm{emp}$. & 0,009 & 0,056 & 0,056 \\
\hline QMS & 50 to $250 \mathrm{emp}$. & 0,250 & 0,691 & 0,697 \\
\hline QMS & Male & 0,036 & 0,211 & 0,212 \\
\hline QMS & Female & 0,052 & 0,282 & 0,283 \\
\hline HRM & up to 10 emp. & 0,203 & 0,724 & 0,725 \\
\hline HRM & $\begin{array}{c}\text { from } 10 \text { to } 50 \\
\text { emp. }\end{array}$ & 0,014 & 0,085 & 0,086 \\
\hline HRM & $\begin{array}{c}\text { from } 50 \text { to } 250 \\
\text { emp. }\end{array}$ & 0,151 & 0,506 & 0,511 \\
\hline HRM & Male & 0,073 & 0,382 & 0,382 \\
\hline HRM & Female & 0,074 & 0,376 & 0,377 \\
\hline
\end{tabular}

The results from the ordered regression analysis vary from very low values 0,014 for McFadden's $R^{2}$, to moderately high values 0,725 for Nagelkerke's $R^{2}$.

First, the McFadden's values indicate that there is an excellent model fit when the following construct/control pairs are observed: QMS/50 to 250 employees $(0,250)$; and HRM/up to 10 employees $(0,203)$. In the same column, moderate values are observed with PQ and up to 10 employees $(0,131)$; PQ and 50 to 250 employees $(0,181)$; QMS and up to 10 employees $(0,120)$; and HRM and from 50 to 250 employees $(0,151)$. Every other value in this column indicates a bad model fit. Furthermore, the values in the Cox-Snell column and Nagelkerke column are acceptable, with the exception of the QMS construct and the 10 to 50 employees control, and the HRM construct and also the 10 to 50 employees control. Based on these findings, it is proposed that the null hypotheses is failed to be rejected. Why? There is a chance of sampling error in the instances where the regression values are inadequate. Taking into consideration that every other regression analysis was adequate, it would be incorrect to reject the null hypothesis. Furthermore, to ensure internal consistency of the measured items, a reliability test was conducted. The results are presented in Tab. 6 .

Table 6 Results of the reliability test

\begin{tabular}{|c|c|c|}
\hline \multicolumn{3}{|c|}{ Reliability test } \\
\hline Dimension & Cronbach's alpha & Number of items \\
\hline PDI & 0,94 & 14 \\
\hline PQ & 0,74 & 5 \\
\hline QMS & 0,83 & 4 \\
\hline HRM & 0,79 & 6 \\
\hline BPC & 0,90 & 12 \\
\hline
\end{tabular}

The reliability test produced adequate Cronbach's alpha values, thus the internal consistency of the internal items can be confirmed.

\section{DISCUSSION}

The research of Hult, Hurley and Knight [12] noted that innovativeness is an important factor when it comes to business performance. Not just that, innovativeness seems 
to positively affect business performance regardless of changes that occur on the market. Interestingly, it was also considered that product innovation does not always result in higher business performance.

Further, in this paper the importance of QMS for business performance is also addressed. Certainly, there is evidence that ISO 9001 QMS and TQM as two impeccable approaches for achieving continuous quality, positively affect time-based performance, operational performance and finally the competitive power of an enterprise. It is important to note one more factor that affects business performance and competitiveness, and that is leadership style. Leadership style often determines the intensity of business performance. Also HRM can surely affect business performance metrics.

However, in the present paper the focus was on the "other side of the coin". Product development and innovation, product quality and QMS were analysed in manufacturing enterprises. HRM was also measured in order to provide a comparative overview within the regression model.

This paper has a substantial contribution to the existing body of literature. It includes key aspects when it comes to performance metrics in manufacturing firms. In addition, researchers, engineers and managers can address this paper for useful information regarding product quality importance, product innovation and product development. Overall, the paper provides a solid basis for future research in this domain.

\section{CONCLUSION}

The conducted research in this study resulted in the fact that the null hypothesis cannot be rejected. It is evident that product development and innovation have a statistically significant impact on business performance and competitiveness. Furthermore, the paper analysed why product development and innovation is an important part of achieving business excellence. The paper produced a regression model that helped to better understand the relationship between the observed constructs. The two main constructs were product development and innovation, and business performance and competitiveness. In addition, the research was broadened with mediating constructs which were product quality, QMS and HRM. The advantage of this type of approach lies in the simplicity of acquiring data. There is no need for detailed revenue reports from the respondents and no sensitive information is collected. When measuring business metrics and other technical metrics, there are two types of approaches that fit this type of research. The first is to address one product, one or two manufacturing enterprises, and to collect detailed information about every business metric. However, enterprises often do not want to provide (with reason) their data on business performance. Therefore, the second approach, which is used in this paper as well, focuses on subjective data collected anonymously from managers and enterprise owners. This way, there is less chance of false data collection. The main limitation of this paper is the lack of industry categorization of the sample. However, this is not a severe limitation, as focusing on one industry would held the risk of bias and it would raise the issue of endogeneity. For future research it is necessary to address several industries from several countries. Afterwards a thorough meta-analysis should be conducted. To support those findings an extensive review of previous literature in this domain should be conducted.

Why is the present paper important? It provides a good basis for future research and it hints subtle guidelines for new measurements in similar studies. After these additional studies are conducted, it is recommended to develop a mathematical model that will solidify the arguments proposed in this research.

\section{Acknowledgement}

This work is a part of the current project TR-35017 funded by the Ministry of Education, Science and Technological Development of the Republic of Serbia.

\section{REFERENCES}

[1] Artz, K. W., Norman, P. M., Hatfield, D. E., \& Cardinal, L. B. (2010). A Longitudinal Study of the Impact of R\&D, Patents, and Product Innovation on Firm Performance. Journal of Product Innovation Management, 27(5), 725-740. https://doi.org/10.1111/j.1540-5885.2010.00747.x

[2] Bučiūnienè, I., \& Kazlauskaitè, R. (2012). The linkage between HRM, CSR and performance outcomes. Baltic Journal of Management, 7(1), 5-24. https://doi.org/10.1108/17465261211195856

[3] Cooper, D. R., Schindler, P. S., \& Sun, J. (2006). Business research methods (Vol. 9). New York: McGraw-Hill Irwin.

[4] Corral de Zubielqui, G., Fryges, H., \& Jones, J. (2017). Social media, open innovation \& HRM: Implications for performance. Technological Forecasting and Social Change. https://doi.org/10.1016/j.techfore.2017.07.014

[5] Danneels, E. (2002). The dynamics of product innovation and firm competences. Strategic Management Journal, 23(12), 1095-1121. https://doi.org/10.1002/smj.275

[6] Edgar, F. \& Geare, A. (2005). HRM practice and employee attitudes: different measures-different results. Personnel review, 34(5), 534-549. https://doi.org/10.1108/00483480510612503

[7] Ernst, H. (2002). Success Factors of New Product Development: A Review of the Empirical Literature. International Journal of Management Reviews, 4(1), 1-40. https://doi.org/10.1111/1468-2370.00075

[8] Farouk, S., Kumar Singh, T. F. B. a. S., Abu Elanain, H. M., Obeidat, S. M., \& Al-Nahyan, M. (2016). HRM practices and organizational performance in the UAE banking sector. International Journal of Productivity and Performance Management, 65(6), 773-791. https://doi.org/10.1108/ijppm-01-2016-0010

[9] Glaister, A. J., Karacay, G., Demirbag, M., \&Tatoglu, E. (2018). HRM and performance-The role of talent management as a transmission mechanism in an emerging market context. Human Resource Management Journal, 28(1), 148-166. https://doi.org/10.1111/1748-8583.12170

[10] Han, B., Sim, K. L., \& Ebrahimpour, M. (2012). Relationships among ISO 9001, competitive dimensions and profitability. International Journal of Services and Operations Management, 11(2), 222-236. https://doi.org/10.1504/IJSOM.2012.045200

[11] Heffernan, M., Harney, B., Cafferkey, K., \&Dundon, T. (2016). Exploring the HRM-performance relationship: the role of creativity climate and strategy. Employee Relations, 38(3), 438-462. https://doi.org/10.1108/er-06-2015-0110

[12] Hult, G. T. M., Hurley, R. F., \& Knight, G. A. (2004). Innovativeness: Its antecedents and impact on business 
performance. Industrial Marketing Management, 33(5), 429438. https://doi.org/10.1016/j.indmarman.2003.08.015

[13] Kotler, P. \& Armstrong, G. (2017). Principles of Marketing $(17 \mathrm{ed}$.). Essex, England: Pearson Education.

[14] Kumar, P., Maiti, J., \& Gunasekaran, A. (2018). Impact of quality management systems on firm performance. International Journal of Quality \& Reliability Management, 35(5), 1034-1059. https://doi.org/10.1108/IJQRM-02-2017-0030

[15] Lin, C. I., \& Jang, W. Y. (2008). Successful ISO 9000 implementation in Taiwan. International Journal of Productivity and Performance Management, 57(8), 600-622. https://doi.org/10.1108/17410400810916044

[16] Mahmoud, M. A., Blankson, C., Owusu-Frimpong, N., Nwankwo, S., \& Trang, T. P. (2016). Market orientation, learning orientation and business performance. International Journal of Bank Marketing, 34(5), 623-648. https://doi.org/10.1108/ijbm-04-2015-0057

[17] Mir, M., Casadesús, M., \& Petnji, L. H. (2016). The impact of standardized innovation management systems on innovation capability and business performance: An empirical study. Journal of Engineering and Technology Management, 41, 26-44. https://doi.org/10.1016/j.jengtecman.2016.06.002

[18] Mondy, W. D. M., Joseph J. (2016). Human Resource Management (14 ed.): Pearson Education Limited.

[19] O'Regan, N, Ghobadian, A, \& Gallear, G. (2005). In search of the drivers of high growth in manufacturing SMEs. Technovation, 26(1), 30-41. https://doi.org/10.1016/j.technovation.2005.05.004

[20] Olson, E. M., Slater, S. F., \& Hult, G. T. M. (2005). The Performance Implications of Fit Among Business Strategy, Marketing Organization Structure, and Strategic Behavior. Journal of Marketing, 69(3), 49-65. https://doi.org/10.1509/jmkg.69.3.49.66362

[21] Paauwe, J. (2009). HRM and performance: Achievements, methodological issues and prospects. Journal of Management Studies, 46(1), 129-142. https://doi.org/10.1111/j.1467-6486.2008.00809.x

[22] Leber, M., Bastic, M., Moody, L., \& Krajnc, M. S. (2018). A study of the impact of ergonomically designed workplaces on employee productivity. Advances in Production Engineering \& Management, 13(1), 107-117. https://doi.org/10.14743/apem2018.1.277

[23] Berlec, T., Kleindienst, M., Rabitsch, C., \& Ramsauer, C. (2017). Methodology to Facilitate Successful Lean Implementation. Strojniski vestnik-Journal of Mechanical Engineering, 63(7-8), 457-465. https://doi.org/10.5545/sv-jme.2017.4302

[24] Popa, H. L. \& Pater, L. R. (2006). The valuation of the enterprises and products competitiveness. Tehnički vjesnik, 13(1, 2), 39-48.

[25] Popović, B. \& Miletić, L. Z. (2016). Six sigma and six sigma system in the function of quality and profits increase. Journal of Engineering Management and Competitiveness (JEMC), 6(2), 129-142. https://doi.org/10.5937/jemc1602129P

[26] Psomas, E. \& Kafetzopoulos, D. (2014). Performance measures of ISO 9001 certified and non-certified manufacturing companies. Benchmarking: An International Journal, 21(5), 756-774. https://doi.org/10.1108/BIJ-04-2012-0028

[27] Safdar, R. (2011). HRM: Performance Relationship: Need for Further Development? International Journal of Public Administration, 34(13), 858-868. https://doi.org/10.1080/01900692.2011.615052

[28] Sheehan, M. (2013). Human resource management and performance: Evidence from small and medium-sized firms. International Small Business Journal, 32(5), 545-570. https://doi.org/10.1177/0266242612465454
[29] Singh, R. K., Garg, S. K., \& Deshmukh, S. G. (2008). Strategy development by SMEs for competitiveness: a review. Benchmarking: An International Journal, 15(5), 525-547. https://doi.org/10.1108/14635770810903132

[30] Terziovski, M. (2010). Innovation practice and its performance implications in small and medium enterprises (SMEs) in the manufacturing sector: a resource-based view. Strategic Management Journal, 31(8), 892-902. https://doi.org/10.1002/smj.841

[31] Tung, J. (2012). A study of product innovation on firm performance. International Journal of Organizational Innovation, 4(3).

[32] Xie, S. \& Hayase, K. (2007). Corporate environmental performance evaluation: a measurement model and a new concept. Business Strategy and the Environment, 16(2), 148168. https://doi.org/10.1002/bse.493

[33] Ahmad, M. F., Zakuan, N., Ahmad, J., \& Takala, J. (2015). Meta-analysis of the TQM impact on business performance amongst regions and countries. International Journal of Industrial and Systems Engineering, 20(2), 155-164. https://doi.org/10.1504/IJISE.2015.069546

\section{Contact information:}

Mihalj BAKATOR, MSc, Research Associate

(Corresponding author)

University of Novi Sad, Technical Faculty "Mihajlo Pupin", Zrenjanin

Djure Djakovica bb, 23000 Zrenjanin, Serbia

E-mail: mihalj.bakator@uns.ac.rs

Dejan ĐORĐEVIĆ, PhD, Professor

University of Novi Sad, Technical Faculty "Mihajlo Pupin", Zrenjanin

Djure Djakovica bb, 23000 Zrenjanin, Serbia

E-mail: dejan.djordjevic@ttzr.rs

Dragan ĆOĆKALO, PhD, Professor

University of Novi Sad, Technical Faculty "Mihajlo Pupin", Zrenjanin

Djure Djakovica bb, 23000 Zrenjanin, Serbia

E-mail: dragan.cockalo@tfzr.rs 